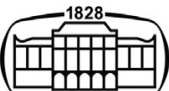

AKADÉMIAI KIADÓ

\section{Acta Veterinaria} Hungarica

$68(2020) 1,37-48$

DOl:

10.1556/004.2020.00005

(C) 2020 Akadémiai Kiadó, Budapest

\section{ORIGINAL ARTICLE}

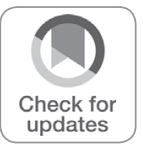

\title{
Expression levels of angiogenic growth factors in feline squamous cell carcinoma
}

YONCA B. KABAK ${ }^{1}$, MAHMUT SOZMEN $^{1 *}$ (1), ALPARSLAN K. DEVRIM ${ }^{2}$, MERT SUDAGIDAN $^{3}$, FUNDA YILDIRIM $^{4}$, TOLGA GUVENC ${ }^{1}$, MURAT YARIM ${ }^{1}$, YAVUZ M. GULBAHAR ${ }^{1}$, ISHTIAQ AHMED ${ }^{5}$, EFE KARACA ${ }^{1}$ and SINEM INAL ${ }^{1}$

\footnotetext{
${ }^{1}$ Department of Pathology, Faculty of Veterinary Medicine, Ondokuz Mayıs University, Kurupelit, 55200 Atakum, Samsun, Turkey

${ }^{2}$ Department of Biochemistry, Faculty of Veterinary Medicine, Kırıkkale University, Kırıkkale, Turkey

${ }^{3}$ Konya Food and Agriculture University, Kit-Argem, Konya, Turkey

${ }^{4}$ Department of Pathology, Faculty of Veterinary Medicine, Istanbul University-Cerrahpaşa, Istanbul, Turkey

${ }^{5}$ Department of Pathology, University of Veterinary and Animal Sciences, Lahore, Pakistan
}

Received: February 8, 2019 • Accepted: November 13, 2019

Published online: May 8, 2020

\section{ABSTRACT}

Squamous cell carcinoma (SCC) is the most common malignant neoplasm of the skin in cats. Tumour angiogenesis is the pivotal event for tumour progression and metastasis. We assessed protein and gene expression of angiogenic growth factors including bFGF, VEGF-C, TGF- $\beta$, PDGF-A, PDGF-C and PDGFR- $\alpha$ that possibly contribute to the angiogenic phenotype of feline SCC (FSCC) and could, therefore, be a good target in the treatment of SCC. In the present study, a total of 27 FSCC cases were investigated. Tumour cases were histopathologically classified as well differentiated (10/27), moderately differentiated (5/27), and poorly differentiated (12/27). The expression levels of the growth factors were detected using immunohistochemistry and assessed semi-quantitatively. Growth factor expression levels were evaluated at different locations: in the oral region, in areas exposed to solar UV radiation including the ears, eyelids and nasal planum, and other miscellaneous locations. Our findings have revealed that FSCC arising from different anatomical sites of the body and showing differences in aggressiveness, metastasis, and prognosis may be angiogenesis dependent, and angiogenic key regulators could play a role in the development of FSCC.

\section{KEYWORDS}

bFGF, feline, PDGF, squamous cell carcinoma, TGF $\beta 1$, VEGF-C

\section{INTRODUCTION}

Squamous cell carcinoma (SCC) is the second most common cancer in humans, and its frequency is increasing worldwide (Weinberg et al., 2007). Similarly, SCC is the most common malignant tumour of the skin and oral cavity in cats. Feline SCC (FSCC) may develop as a solitary mass or in the form of multiple proliferative or ulcerative masses. The ear pinna, the eyelids, the planum nasale, the gingiva, the tongue and the sublingual region are the most commonly affected sites of the skin and oral cavity, respectively (Miller et al., 1991). FSCC is a multifactorial neoplasm and its prevalence is mostly related to exposure to solar UV radiation; it may be preceded by epidermal dysplasia and actinic keratosis (Gross et al., 2005). FSCC is locally invasive and destructive; however, metastases are rare or they 
occur late in the course of the disease (Gross et al., 2005). SCC ranges from well-differentiated carcinomas to anaplastic carcinomas. The metastatic and invasive potential of SCCs is not correlated with the histological grade (Wilcock, 2006).

Tumour angiogenesis is one of the pivotal events for tumour progression and metastasis. Basic fibroblast growth factor (bFGF, FGF-2) and vascular endothelial growth factor (VEGF) have been considered as leading factors in the process of tumour development (Hasina et al., 2008). VEGF is a specific mitogen for vascular endothelial cells and it is produced by various cell types including neoplastic cells (Yoshiji et al., 1996). VEGF-C is a member of the plateletderived growth factor family (Veikkola and Alitalo, 1999) and it activates VEGF receptor-3, a cell surface tyrosine kinase receptor expressed on lymphatic endothelial cells and cancer cells (Witte et al., 2002). VEGF-C induces proliferation, differentiation, and migration of vascular endothelial cells, and enhances capillary permeability (Ferrara and Davis-Smith, 1997; Breslin et al., 2003). Elevated VEGF-C expression has been correlated with histological grade of malignancy in feline tumours (Millanta et al., 2002; Al-Dissi et al., 2007). This is possibly due to the rapid growth of a tumour mass resulting in central necrosis, hypoxia and, thus, stimulating VEGF expression so that the tumour can vascularise and gain sufficient nutrients to sustain its growth. It has been shown that only the tumour cells themselves, but not the surrounding endothelial cells, show enhanced expression of VEGF, which supports the hypothesis that VEGF acts as an autocrine or paracrine factor (Kowanetz and Ferrara, 2006). Taken together, these data suggest that VEGF-C plays a critical role in the progression of tumour growth and metastasis in numerous human and animal tumour systems, but the role that VEGF-C expression plays in motility and invasion in FSCC has not been explored in detail.

Basic fibroblast growth factor (bFGF) is a cytokine associated with the stimulation of angiogenesis and can be produced by many cell types (Galzie et al., 1997). bFGF has potent angiogenic activity and has been identified in a wide variety of malignancies including human head and neck squamous cell carcinomas (Ninck et al., 2003; Montag et al., 2009). bFGF increases vessel density by inducing VEGF activity (Asahara et al., 1995).

Transforming growth factor- $\beta$ (TGF- $\beta$ ) is a large superfamily of growth-regulatory molecules, and three isoforms (TGF- $\beta 1$, TGF- $\beta 2$, and TGF- $\beta 3$ ) have been identified in mammals, with TGF- $\beta 1$ being the predominant one in most tissues including the skin (Wang, 2001). TGF- $\beta 1$ plays a significant role in the maintenance of tissue homeostasis homoeostasis through the regulation of biological processes including cell proliferation, differentiation, apoptosis, angiogenesis, and carcinogenesis (Feng and Derynck, 2005). Elevated TGF- $\beta 1$ levels are associated with poor prognosis in various human cancers, enhancing tumour invasion via the paracrine effects of TGF- $\beta 1$ on tumour stroma, modulating angiogenesis (Ulloa et al., 1999). However, it was also demonstrated that TGF- $\beta 1$ overexpression suppresses mammary tumourigenesis in humans (Pierce et al., 1995). Thus, these contrasting effects indicate the dual role of TGF$\beta 1$ in tumours. TGF- $\beta 1$ acts as a growth inhibitor in early tumour stages but it contributes to tumour progression and invasiveness in more advanced diseases (Akhurst and Derynck, 2001).

Platelet-derived growth factor (PDGF) is a $30 \mathrm{kDa}$ dimeric molecule, composed of two disulphide-linked polypeptide chains designated as $A$ and $B$ that dimerise in all possible combinations: PDGF-AA, PDGF-BB and PDGF-AB (Andrae et al., 2008). The PDGF isoforms exert their cellular effects by binding to a dimeric tyrosine kinase receptor consisting of $\alpha$ and/or $\beta$ subunits (Alvarez et al., 2006; Ostman and Heldin, 2007). PDGF ligands and receptors are of major importance in angiogenesis (Alvarez et al., 2006; Ostman and Heldin, 2007), cell proliferation, chemotaxis, and survival in neoplastic cells (Heldin and Westermark, 1999). Platelet-derived growth factor receptor (PDGFR) regulates normal cellular growth and differentiation (Ross et al., 1986), and the expression of activated PDGFR promotes oncogenic transformation, suggesting that activating mutations or gene rearrangements could play a role in tumourigenesis (Gazit et al., 1984). Although elevated PDGF expression has been reported in human SCC, where it contributes to tumour growth in an autocrine manner and stimulates angiogenesis and tumour growth (Montag et al., 2009), there is a scarcity of studies in cats showing its role in the development of feline cancers (Katayama et al., 2004). Nor are there studies investigating the simultaneous expression of different angiogenic growth factors in cancers occurring in animals. Moreover, the knowledge about the complex interactions between growth factors is still incomplete and their functional activity is not restricted to angiogenesis alone. A more detailed understanding of the regulatory pathways and the interactions between growth factors in SCCs is essential for improving the clinical prognosis of this tumour type. Therefore, we assessed the protein and gene expression profiles of a panel of angiogenic growth factors including bFGF, VEGF-C, PDGF-A, PDGFC, PDGFR- $\alpha$ and TGF- $\beta 1$ in native tumour tissues that possibly contribute to the angiogenic phenotype of FSCC and could therefore serve as a good therapeutic target.

\section{MATERIALS AND METHODS}

\section{Animals and histopathology}

Formalin-fixed paraffin wax-embedded (FFPE) samples from 27 different FSCCs were selected from the archives of the Department of Pathology. Additionally, control tissues were collected from locations most frequently affected by SCCs (dorsal part of the tongue, cheek mucosa, hard palate, nasal planum, lips, eyelids, ear pinna) from five cats (four female and one male). Control tissues were collected during routine necropsies of cats that had died of diseases other than endocrine and skin diseases. For each sample, sections $(5 \mu \mathrm{m})$ were stained with haematoxylin and eosin (HE). 
The grading scheme of SCCs was based largely on the criteria suggested by Goldschmidt et al. (1998). Differentiation was scored from 1 to 3 on the basis of keratinisation as follows: SCCs showing abundant large concentric laminated keratin masses (keratin pearls), large tumour islands, prominent intercellular bridges, apparent squamous differentiation, cells with abundant eosinophilic cytoplasm were graded as well differentiated (Grade 1). Carcinomas with a moderate degree of keratinisation and differentiation, exhibiting rare small- to medium-sized keratin pearls, smaller islands, still with spinous differentiation but with an elevated number of poorly differentiated cells were graded as moderately differentiated (Grade 2). Carcinomas showing no sign of keratinisation or few individual cells exhibiting signs of keratinisation, few small tumour islands, poor cellular differentiation and absence of intercellular bridges were graded as poorly differentiated (Grade 3).

\section{Immunohistochemistry (IHC)}

Sections $(5 \mu \mathrm{m})$ from the tissue samples were subjected to immunohistochemistry (IHC) using the streptavidin-biotin peroxidase complex technique for the detection of bFGF, VEGF-C, TGF $\beta 1$, PDGF-A, PDGF-C and PDGFR- $\alpha$. Comparison of the VEGF and PDGF cDNA sequence among different species revealed that members of the VEGF and PDGF families are highly conserved (Cheung and Brace, 1998; Andrae et al., 2008).

Serial sections were dewaxed in xylene and hydrated through graded alcohols. Endogenous peroxidase activity was blocked with $3 \% \mathrm{H}_{2} \mathrm{O}_{2}$ in absolute methanol for $15 \mathrm{~min}$. The sections were rinsed with phosphate buffered saline (PBS, $\mathrm{pH} 7.2)$ and subsequently heated in citrate buffer $(\mathrm{pH}$ $6.0)$ in a microwave oven $(600 \mathrm{~W})$ for $10 \mathrm{~min}$ for antigen retrieval. After washing with PBS the sections were incubated with each of the primary antibodies (Table 1). Following brief rinsing with PBS the sections were incubated with biotinylated goat anti-rabbit IgG (bFGF, PDGFR- $\alpha$, TGF $\beta 1$ ), biotinylated rabbit anti-mouse IgG (VEGF-C, PDGF-A) or biotinylated rabbit anti-goat IgG (PDGF-C), all at a dilution of 1:300 in PBS for $30 \mathrm{~min}$ at room temperature

Table 1. Primary antibodies used for immunohistochemistry

\begin{tabular}{lcc}
\hline Primary antibody & Dilution & Source (product codes) \\
\hline $\begin{array}{c}\text { Polyclonal rabbit anti- } \\
\text { human bFGF }\end{array}$ & $1: 100$ & Santa Cruz $^{\mathrm{a}}$ (147; sc-79) \\
$\begin{array}{c}\text { Monoclonal mouse anti- } \\
\text { human VEGF-C }\end{array}$ & $1: 100$ & Santa Cruz (C-1; sc-7269) \\
$\begin{array}{c}\text { Monoclonal mouse anti- } \\
\text { human PDGF-A }\end{array}$ & $1: 100$ & Santa Cruz (E-10; sc-9974) \\
$\begin{array}{c}\text { Polyclonal goat anti- } \\
\text { human PDGF-C }\end{array}$ & $1: 50$ & Santa Cruz (C-17; sc-18228) \\
$\begin{array}{c}\text { Polyclonal rabbit anti- } \\
\text { human PDGFR- } \alpha\end{array}$ & $1: 400$ & Santa Cruz (C-20; sc-338) \\
$\begin{array}{c}\text { Polyclonal rabbit anti- } \\
\text { human TGF } \beta 1\end{array}$ & $1: 100$ & Santa Cruz (V; sc-146) \\
\hline
\end{tabular}

${ }^{\text {a }}$ Santa Cruz Laboratories, Santa Cruz, California, USA.
(RT). Secondary antibodies were supplied by Dako (Carpinteria, California, USA). After further washing with PBS, all sections were treated with streptavidin-peroxidase complex (Dako) at a dilution of 1:300 for $30 \mathrm{~min}$ at RT. Labelling was 'visualised' with amino ethyl carbazole (AEC substrate kit; Invitrogen, Camarillo, Canada) as the chromogen. Sections were counterstained with Harris' haematoxylin for 1 min, rinsed with tap water, and mounted with an aqueous mounting medium (Vision Mount; Lab Vision, USA). Primary antibodies were omitted from negative control sections, which were incubated with normal serum from which the primary antibody was raised.

\section{Evaluation of immunostaining}

Tissue sections were scored semi-quantitatively for immunolabelling. An area with the highest density of positivelylabelled neoplastic cells was chosen. The percentage of cells labelled and the extent of reactivity in the tumour cells was evaluated at $\times 200$ final magnification with an eyepiece showing grids of 100 squares from a total of 10 different adjacent fields measuring a total area of $0.050 \mathrm{~mm}^{2}$. Labelling intensity was also quantified using a four-point score: 0 , no labelling; 1, weak labelling; 2, moderate labelling; and 3, intense immunolabelling. An immunoreactivity score (IRS) was obtained by multiplying the immunolabelling intensity score $(0-3)$ by the percentage of immunolabelled cells within the total area of $0.050 \mathrm{~mm}^{2}$. The IRS ranged from 0 to a maximum value of 300 .

\section{Real-time (RT-) PCR}

Total RNA was isolated from 27 FFPE tumour tissue and five control tissue samples using a commercial RNA isolation kit (High Pure RNA Paraffin Kit, Cat No./ID: 03270289001, Roche) including on-column DNase treatment to remove genomic DNA. The concentration and purity of total RNA samples were determined using a drop plate reader (Multiskan ${ }^{\mathrm{TM}} \mathrm{GO}$, Microplate Spectrophotometer, Thermo Scientific) by measuring their absorbance values at 260 and $280 \mathrm{~nm}$ and calculating the A260/A280 ratio. cDNA synthesis was performed using a commercial cDNA synthesis kit (\#K1682, Maxima H Minus First Strand cDNA Synthesis with dsDNase, Thermo Scientific). The synthesised cDNA samples were quantified and $200 \mathrm{ng}$ cDNA of each tumour tissue sample was used to amplify genes the details of which are given in Table 2. LightCycler ${ }^{\circledR}$ 480 SYBR Green I Master Kit (Cat No./ID: 04707516001, Roche) was used and all PCR reactions were normalised to GAPDH. Crossing point $(\mathrm{Cp})$ values of the amplified genes were used to determine relative expressions of genes with respect to GAPDH. The fold changes were determined using the equation $2^{\wedge-\Delta \Delta C t}$. If the fold change was greater than 1 , the result was evaluated as fold-upregulation. If the fold change was less than 1 , the negative inverse of the result was regarded as fold downregulation. 
Table 2. Details of primers used in real-time PCR analysis

\begin{tabular}{|c|c|c|}
\hline Gene & Base sequence $\left(5^{\prime} \rightarrow 3^{\prime}\right)$ & $\begin{array}{l}\text { Amplikon } \\
\text { size (bp) }\end{array}$ \\
\hline \multirow[t]{2}{*}{ bFGF } & F: GAGAAGAGCGACCCTCACAT & \multirow[t]{2}{*}{65} \\
\hline & R: TTGATGGACACAACCCCTCT & \\
\hline \multirow[t]{2}{*}{ VEGF-C } & F: ACCTGCAAGGATACGTGGTC & \multirow[t]{2}{*}{60} \\
\hline & R: AACAAGCACCGAGGTTTCAA & \\
\hline \multirow[t]{2}{*}{ TGF- $\beta 1$} & F: GAGCCCAAGGGCTACCAC & \multirow[t]{2}{*}{61} \\
\hline & R: CCAGGCTCCAGATGTAGGG & \\
\hline \multirow{2}{*}{ PDGF-A } & F: GAGACCCGTCTCCCATCA & \multirow[t]{2}{*}{69} \\
\hline & R: GGGCTACTCCAAGTGATCGT & \\
\hline \multirow[t]{2}{*}{ PDGF-C } & F: ACGGCTCTTTTGAGAGGAGA & \multirow[t]{2}{*}{61} \\
\hline & R: TTTTTCCAGGACCAAAGACC & \\
\hline \multirow[t]{2}{*}{ PDGFR- $\alpha$} & F: GACTGTGAGATGCACAGCAGA & \multirow[t]{2}{*}{60} \\
\hline & R: TTGCAAATCATCCACTCGATA & \\
\hline \multirow[t]{2}{*}{ GAPDH } & F: GATCCCGCCAACATCAAAT & \multirow[t]{2}{*}{67} \\
\hline & R: TGAAGACCCCAGTAGACTCCA & \\
\hline
\end{tabular}

\section{Statistical analysis}

All the data were expressed as means \pm SE. Assessment of the results was performed using one-way ANOVA. Differences between groups were analysed with a nonparametric analysis of variance (Kruskal-Wallis test), followed by post hoc group comparisons with the Mann-Whitney U test. For all the statistical analysis GraphPad Prism 5 statistical software (GraphPad Software Inc., La Jolla, CA, USA) was used. Statistical significance was determined as a $P$ value below 0.05 .

\section{RESULTS}

\section{Signalment and history}

All cats were Domestic Shorthair (DSH); five were males, 15 were females, and the sex of seven cases was not determined. The mean age at the time of diagnosis was 11.4 years (range: 517 years). Five cats were white coated. Ten of the spontaneous FSCCs occurred on the ear pinna, seven on the eyelids, seven in the oral region, and one case each on the nasal planum, in the perineal region and the mandibular area. Details of the animals and tumour regions are given in Table 3.

\section{Histopathological findings}

All the tumours were graded according to the criteria mentioned in the Materials and methods with 10 welldifferentiated (grade 1, 37\%; Fig. 1a), five moderately differentiated (grade 2, 18.5\%; Fig. 1b), and 12 poorly differentiated (grade 3, 44.4\%; Fig. 1c) SCCs (Table 3). However, six of the seven carcinomas located in the oral region were poorly differentiated and the remaining one case was moderately differentiated.

\section{Immunohistochemistry}

The immunohistochemical staining scores are summarised in Tables 4-6.
Table 3. Clinical and histopathological characteristics of 27 cats with SCCs

\begin{tabular}{|c|c|c|c|c|c|}
\hline $\begin{array}{l}\text { Case } \\
\text { no. }\end{array}$ & $\begin{array}{c}\text { Age } \\
\text { (years) }\end{array}$ & Sex & Breed & Tumour site & $\begin{array}{l}\text { SCC } \\
\text { grade }^{\mathrm{a}}\end{array}$ \\
\hline 1 & 13 & $\mathrm{~F}$ & DSH & Tongue & 3 \\
\hline 2 & 15 & $\mathrm{~F}$ & DSH & Tongue & 3 \\
\hline 3 & 15 & ND & DSH & Buccal mucosa & 3 \\
\hline 4 & 17 & $\mathrm{~F}$ & DSH & Buccal mucosa & 3 \\
\hline 5 & 14 & M & DSH & $\begin{array}{l}\text { Gingiva and hard } \\
\text { palate }\end{array}$ & 3 \\
\hline 6 & 10 & ND & DSH & Sublingual region & 3 \\
\hline 7 & 9 & $\mathrm{~F}$ & DSH & $\begin{array}{l}\text { Sublingual region } \\
\text { and tonsil }\end{array}$ & 2 \\
\hline 8 & 8 & $\mathrm{~F}$ & DSH & Ear pinna & 1 \\
\hline 9 & 13 & ND & DSH & Ear pinna & 1 \\
\hline 10 & 13 & $\mathrm{~F}$ & $\begin{array}{c}\text { DSH } \\
\text { white }\end{array}$ & Ear pinna & 1 \\
\hline 11 & 13 & $\mathrm{~F}$ & DSH & Ear pinna & 2 \\
\hline 12 & 5 & M & $\begin{array}{l}\text { DSH } \\
\text { white }\end{array}$ & Ear pinna & 2 \\
\hline 13 & 12 & ND & DSH & Ear pinna & 2 \\
\hline 14 & 8 & $\mathrm{~F}$ & $\begin{array}{l}\text { DSH } \\
\text { white }\end{array}$ & Ear pinna & 3 \\
\hline 15 & 6 & $\mathrm{~F}$ & $\begin{array}{l}\text { DSH } \\
\text { white }\end{array}$ & Ear pinna & 3 \\
\hline 16 & 10 & ND & $\begin{array}{l}\text { DSH } \\
\text { white }\end{array}$ & Ear pinna & 3 \\
\hline 17 & 10 & $\mathrm{~F}$ & DSH & Ear pinna & 3 \\
\hline 18 & ND & ND & DSH & Eyelid & 1 \\
\hline 19 & ND & ND & DSH & Eyelid & 1 \\
\hline 20 & 8 & M & DSH & Eyelid & 1 \\
\hline 21 & 10 & M & DSH & Eyelid & 1 \\
\hline 22 & 10 & $\mathrm{~F}$ & DSH & Eyelid & 1 \\
\hline 23 & 14 & $\mathrm{~F}$ & DSH & Eyelid & 3 \\
\hline 24 & 16 & $\mathrm{~F}$ & DSH & Eyelid & 3 \\
\hline 25 & 12 & $\mathrm{~F}$ & DSH & Nasal planum & 1 \\
\hline 26 & 12 & $\mathrm{~F}$ & DSH & Perineal region & 1 \\
\hline 27 & 13 & M & DSH & Mandibular joint & 2 \\
\hline
\end{tabular}

M, male; F, female; DSH, Domestic Shorthair; ND: not determined. a(1) well differentiated; (2) moderately differentiated; (3) poorly differentiated.

\section{bFGF}

Control tissues collected from locations most frequently affected by FSCC revealed diffuse cytoplasmic staining of epithelial cells from the epidermis (IRS: $63.86 \pm 16.85$; Fig. 1d). Tumours were labelled by the bFGF-specific antibody in 25/27 cases (92.6\%). Two grade 1 FSCC cases (cases no. 18 and 20) from the eyelids were negative for the bFGFspecific antibody. All positive FSCC cases showed cytoplasmic pattern of bFGF expression. The staining intensity was stronger in the outer cells of keratin pearls (Fig. 1e). Immunoreactivity scores were not significantly different between FSCC from the oral region (IRS: $86.36 \pm 39.88$ ) and FSCCs from the eyelids, ear pinna and nasal planum (IRS: $92.83 \pm 20.76$ ) (Table 4). There was no significant difference between tumour grade and IRS for bFGF staining (Tables 5 and 6). 




Figure 1. Histopathological and immunohistochemical staining results for bFGF, VEGF-C, TGF $\beta 1$, PDGF-A, PDGF-C and PDGFR- $\alpha$ in the FSCC cases: (a) Well-differentiated (Grade 1) FSCC from ear pinna. The tumour is composed of islands and trabeculae of neoplastic epithelial cells, showing squamous differentiation. Presence of variable-sized dense laminated keratin. Case no. 9, HE, Bar $=425 \mu \mathrm{m}$; (b) Moderately differentiated (Grade 2) FSCC from ear pinna with occasional presence of small keratinised islands (arrows) in a stroma with an elevated number of poorly differentiated cells. Case no. 11, HE, Bar $=85 \mu \mathrm{m}$; (c) Poorly differentiated (Grade 3) FSCC from the hard palate with no keratinisation. Epithelial cells are forming cords and nests. Case no. 5, HE, Bar $=85 \mu \mathrm{m}$; (d) Diffuse cytoplasmic staining of epithelial cells from the epidermis (arrows). Control tissue from eyelid. bFGF, IHC, Bar $=85 \mu \mathrm{m}$; (e) Neoplastic epithelial cells forming islands and nests from well-differentiated FSCC of the nasal planum show intense cytoplasmic bFGF labelling (arrows). Case no. 25, bFGF, IHC, Bar $=85 \mu \mathrm{m}$; (f) Diffuse cytoplasmic staining of epithelial cells from epidermis (arrows). Control tissue from ear pinna. VEGF-C, IHC, Bar $=170 \mu \mathrm{m}$; (g) Intense cytoplasmic VEGF-C labelling of the neoplastic epithelial cells of poorly differentiated FSCC from the hard palate. Case no. 5, VEGF-C, IHC, Bar $=170 \mu \mathrm{m}$; (h) Intense cytoplasmic TGF- $\beta$ labelling of the neoplastic epithelial cells of poorly differentiated FSCC from the gingiva and hard palate. Case no. 5, TGF- $\beta$, IHC, Bar $=85 \mu \mathrm{m}$; (i) Epithelial cells from the epidermis are generally negative or show very weak cytoplasmic staining (arrows). Control tissue from the eyelid. PDGF-A, IHC, Bar $=85 \mu \mathrm{m}$; (j) Intense and diffuse cytoplasmic PDGF-A labelling of the neoplastic epithelial cells forming islands and nests from well-differentiated FSCC of the eyelids. Case no. 19, PDGF-A, IHC, Bar $=85 \mu \mathrm{m}$; (k) Moderate and diffuse cytoplasmic PDGF-A labelling of the neoplastic epithelial cells from a moderately differentiated FSCC of the ear pinna. Case no. 11, PDGF-A, IHC, Bar $=85 \mu \mathrm{m}$; (l) Epithelial cells from the epidermis show weak but diffuse cytoplasmic staining (arrows). Control tissue from the nasal planum. PDGF-C, IHC, Bar $=85 \mu \mathrm{m} ;(\mathrm{m})$ Moderate cytoplasmic PDGF-C labelling of the neoplastic epithelial cells from well-differentiated FSCC of eyelids. Case no. 22, PDGF-C, IHC, Bar $=85 \mu \mathrm{m}$; (n) Epithelial cells from the epidermis show weak cytoplasmic and nuclear staining (arrows). Control tissue from the eyelid. PDGFR- $\alpha$, IHC, Bar $=85 \mu \mathrm{m}$; (o) Mainly cytoplasmic and nuclear labelling of the tumour cells from a moderately differentiated FSCC of the ear pinna. Case no. 11, PDGFR- $\alpha$, IHC, Bar $=85 \mu \mathrm{m}$; (p) Both cytoplasmic and nuclear labelling of the tumour cells from a poorly differentiated FSCC of the eyelids. Case no. 23, PDGFR- $\alpha$,

IHC, Bar $=85 \mu \mathrm{m}$ 
Table 4. Summary of immunoreactivity scores for growth factors in FSCC considering only tumour location

\begin{tabular}{lrccccrc}
\hline SCC location & $n$ & bFGF & VEGF-C & TGF- $\beta$ & PDGF-A & PDGF-C & PDGFR- $\alpha$ \\
\hline Oral region & 7 & $86.36 \pm 39.88$ & $70.00 \pm 34.02^{\mathrm{a}}$ & $15.71 \pm 15.71$ & $87.86 \pm 26.79^{\mathrm{a}}$ & $2.71 \pm 1.45$ & $103.1 \pm 29.45$ \\
Ear, eyelid, nose & 18 & $92.83 \pm 20.76$ & $24.64 \pm 10.02^{\mathrm{b}}$ & $0.55 \pm 0.55^{\mathrm{a}}$ & $94.56 \pm 17.77^{\mathrm{a}}$ & $29.44 \pm 7.91$ & $90.72 \pm 23.09$ \\
Other & 2 & $160.00 \pm 0.00$ & $0.00 \pm 0.00$ & $10.00 \pm 10.00^{\mathrm{b}}$ & $220.0 \pm 30.00^{\mathrm{a}}$ & $65.00 \pm 25.00$ & $95.00 \pm 5.00$ \\
Control & 5 & $63.86 \pm 16.85$ & $75.47 \pm 17.51^{\mathrm{a}}$ & $0.00 \pm 0.00^{\mathrm{ac}}$ & $26.13 \pm 9.06^{\mathrm{b}}$ & $17.50 \pm 5.45$ & $39.48 \pm 11.02$ \\
\hline
\end{tabular}

Values are presented as mean $\pm \mathrm{SE} ; \mathrm{a}, \mathrm{b}, \mathrm{c}$, column groups denoted with different letters indicate statistically significant difference $(P<0.05)$. The labelling intensity for the neoplastic cells is scored as: 0 , none; 1 , weak; 2 , moderate; 3 , intense. Multiplication of the grades for intensity and percentage scores gives an immunoreactivity score with a maximum value of 300 .

Table 5. Immunoreactivity scores for growth factors in FSCC considering only tumour grade

\begin{tabular}{|c|c|c|c|c|c|c|c|}
\hline Grade & $n$ & bFGF & VEGF-C & TGF- $\beta$ & PDGF-A & PDGF-C & PDGFR- $\alpha$ \\
\hline 1 & 10 & $107.0 \pm 24.35$ & $15.75 \pm 9.28$ & $3.00 \pm 2.13$ & $109.2 \pm 30.34^{\mathrm{a}}$ & $27.00 \pm 10.68$ & $93.00 \pm 30.08$ \\
\hline 2 & 5 & $94.20 \pm 52.50$ & $0.60 \pm 0.60^{\mathrm{a}}$ & $0.00 \pm 0.00$ & $98.00 \pm 40.30$ & $48.00 \pm 20.35$ & $70.50 \pm 45.42$ \\
\hline 3 & 12 & $87.88 \pm 27.13$ & $64.42 \pm 22.11$ & $9.16 \pm 9.16$ & $97.92 \pm 17.99^{\mathrm{a}}$ & $14.08 \pm 6.06$ & $105.2 \pm 23.59^{\mathrm{a}}$ \\
\hline Control & 5 & $63.86 \pm 16.85$ & $75.47 \pm 17.51^{\mathrm{b}}$ & $0.00 \pm 0.00$ & $26.13 \pm 9.06^{\mathrm{b}}$ & $17.50 \pm 5.45$ & $39.48 \pm 11.02^{\mathrm{b}}$ \\
\hline
\end{tabular}

Values are presented as mean \pm SE; $a, b, c$, column groups denoted with different letters indicate statistically significant difference $(P<0.05)$. The labelling intensity for the neoplastic cells is scored as: 0 , none; 1 , weak; 2 , moderate; 3 , intense. Multiplication of the grades for intensity and percentage scores gives an immunoreactivity score with a maximum value of 300 .

Table 6. Immunoreactivity scores for growth factors in FSCC considering both tumour location and grade

\begin{tabular}{|c|c|c|c|c|c|c|c|c|}
\hline SCC location & $n$ & Grade & bFGF & VEGF-C & TGF- $\beta$ & PDGF-A & PDGF-C & PDGFR- $\alpha$ \\
\hline \multirow[t]{2}{*}{ Oral region } & 1 & 2 & $1.00 \pm 0.00$ & $0.00 \pm 0.00$ & $0.00 \pm 0.00$ & $20.00 \pm 0.00$ & $0.00 \pm 0.00$ & $1.50 \pm 0.00$ \\
\hline & 6 & 3 & $100.6 \pm 44.09$ & $81.67 \pm 37.81$ & $18.33 \pm 18.33^{\mathrm{a}}$ & $99.17 \pm 28.73^{\mathrm{a}}$ & $3.16 \pm 1.64$ & $120.0 \pm 28.52^{\mathrm{a}}$ \\
\hline Control & 5 & & $63.86 \pm 16.85$ & $75.47 \pm 17.51$ & $0.00 \pm 0.00^{\mathrm{b}}$ & $26.13 \pm 9.06^{\mathrm{b}}$ & $17.50 \pm 5.45$ & $39.48 \pm 11.02^{\mathrm{b}}$ \\
\hline \multirow[t]{3}{*}{ Ear, eyelid, nose } & 9 & 1 & $101.1 \pm 26.42$ & $17.50 \pm 10.19$ & $1.11 \pm 1.11$ & $93.56 \pm 29.07^{\mathrm{a}}$ & $25.56 \pm 11.83$ & $92.22 \pm 33.61$ \\
\hline & 3 & 2 & $103.3 \pm 83.53$ & $1.00 \pm 1.00$ & $0.00 \pm 0.00$ & $93.33 \pm 54.57$ & $50.00 \pm 26.46$ & $87.00 \pm 76.70$ \\
\hline & 6 & 3 & $75.17 \pm 35.09$ & $47.17 \pm 24.53$ & $0.00 \pm 0.00$ & $96.67 \pm 24.45^{\mathrm{a}}$ & $25.00 \pm 10.57$ & $90.33 \pm 39.35$ \\
\hline Control & 5 & & $63.86 \pm 16.85$ & $75.47 \pm 17.51$ & $0.00 \pm 0.00$ & $26.13 \pm 9.06^{\mathrm{b}}$ & $17.50 \pm 5.45$ & $39.48 \pm 11.02$ \\
\hline \multirow[t]{2}{*}{ Other regions } & 1 & 1 & $160.0 \pm 0.00$ & $0.00 \pm 0.00$ & $20.0 \pm 0.00^{\mathrm{a}}$ & $250.0 \pm 0.00$ & $40.00 \pm 0.00$ & $100.0 \pm 0.00$ \\
\hline & 1 & 2 & $160.0 \pm 0.00$ & $0.00 \pm 0.00$ & $0.00 \pm 0.00^{\mathrm{b}}$ & $190.0 \pm 0.00$ & $90.00 \pm 0.00$ & $90.00 \pm 0.00$ \\
\hline Control & 5 & & $63.86 \pm 16.85$ & $75.47 \pm 17.51$ & $0.00 \pm 0.00^{\mathrm{b}}$ & $26.13 \pm 9.06$ & $17.50 \pm 5.45$ & $39.48 \pm 11.02$ \\
\hline
\end{tabular}

Values are presented as mean $\pm \mathrm{SE} ; \mathrm{a}, \mathrm{b}, \mathrm{c}$, column groups denoted with different letters indicate statistically significant difference $(P<0.05)$. The labelling intensity for the neoplastic cells is scored as: 0 , none; 1 , weak; 2 , moderate; 3 , intense. Multiplication of the grades for intensity and percentage scores gives an immunoreactivity score with a maximum value of 300 .

\section{VEGF-C}

Control tissue immunostaining revealed diffuse cytoplasmic staining of epithelial cells, with the staining intensity ranging from negative to intense (IRS: $75.47 \pm 17.51$; Fig. 1f). FSCC tissue sections were labelled by the VEGF-C-specific antibody in $13 / 27$ cases (48.1\%). All positive FSCC cases showed cytoplasmic pattern of VEGF-C expression (Fig. 1g). Immunoreactivity scores (IRS: $70.00 \pm 34.02$ ) were significantly higher $(P<0.05)$ in the tumours occurring in the oral region than in FSCC cases from the eyelids, ear pinna and nasal planum (IRS: $24.64 \pm 10.02$, Table 4). IRS were also higher in the poorly differentiated (Grade 3) FSCC (IRS: $64.42 \pm 22.11$ ) compared to well-differentiated (Grade 1) FSCC (IRS: $15.75 \pm 9.28$ ). However, the difference was not statistically significant (Tables 5 and 6 ).
TGF- $\beta$

Control tissue immunostaining was negative for all the tissues collected from the dorsal part of the tongue, from the cheek mucosa, hard palate, nasal planum, lips, eyelids and ear pinna. FSCC cases were labelled by the TGF- $\beta$-specific antibody only in $3 / 27$ cases (cases no. 5,10 , and $26 ; 11.1 \%$ ). All positive tumours had a cytoplasmic pattern of TGF- $\beta$ expression (Fig. 1h). Immunoreactivity scores were higher in FSCC cases occurring in the oral region (IRS: $15.71 \pm 15.71$ ) than in FSCC from the eyelids, ear pinna and nasal planum (IRS: $0.55 \pm 0.55$ ) and FSCC from other areas (IRS: $10.00 \pm$ $10.00)$ with no statistically significant difference (Tables 4 and 5). However, IRSs were significantly higher $(P<0.05)$ in the poorly differentiated grade 3 FSCC from the oral region (IRS: 18.33) compared to the control skin tissues (Table 6). 


\section{PDGF-A}

Control tissues were either negative or revealed a low IRS for all the tissues collected from the dorsal part of the tongue and from the cheek mucosa, hard palate, nasal planum, lips, eyelids, and ear pinna (Fig. 1i). On the other hand, FSCC cases were labelled by the PDGF-A-specific antibody in 26/ 27 cases $(96.3 \%)$. All positive FSCC cases revealed a cytoplasmic pattern of PDGF-A labelling (Fig. $1 \mathrm{j}$ and $1 \mathrm{k}$ ). The IRS was significantly higher in the FSCC occurring in the oral region (IRS: $87.86 \pm 26.79$ ) and in FSCC from the eyelids, ear pinna and nasal planum (IRS: $94.56 \pm 17.77$ ) compared to the control tissues (IRS: $26.13 \pm 9.06$; $P<0.05$ ). Furthermore, the difference was also significant when only the tumour grade was considered (Tables 4 and 5).

\section{PDGF-C}

Control tissues revealed a low IRS for all the tissues collected from the dorsal part of the tongue and from the cheek mucosa, hard palate, nasal planum, lips, eyelids, and ear pinna (Fig. 11). Tumours were labelled by the PDGF-Cspecific antibody in $17 / 27$ cases $(63 \%)$. All positive tumours exhibited a cytoplasmic pattern of PDGF-C expression (Fig. 1m). Although IRS was higher in FSCC from the ear, eyelid and nasal planum (IRS: $29.44 \pm 7.91$ ) compared to the tumour occurring in the oral region (IRS: $2.71 \pm 1.45$ ), the difference was not statistically significant.

\section{PDGFR- $\alpha$}

Control tissues revealed a low IRS for all the tissues collected from the dorsal part of the tongue and from the cheek mucosa, hard palate, nasal planum, lips, eyelids, and ear pinna (Fig. 1n). Tumours were labelled by the PDGFR- $\alpha$ specific antibody in $24 / 27$ cases (88.8\%). PDGFR- $\alpha$ signals were mainly located in the nuclei; however, in some cases signals were detected only in the cytoplasm or in both the cytoplasm and the nuclei of the neoplastic cells (Fig. 10 and 1p). The IRS was not significantly different between tumours occurring in the oral region (IRS: $103.1 \pm 29.45$ ) and tumours from the eyelids, ear pinna, and nasal planum (IRS: $90.72 \pm 23.09)$. The difference was not statistically significant between the IRS and the tumour grades (Table 6).

\section{Real-time PCR}

We further corroborated our findings by quantitative RTPCR. Alteration in the gene expressions at mRNA levels in all 27 FSCC cases were compared with healthy feline skin tissues collected from five cats. The bFGF and PDGF-A genes were upregulated in the FSCC cases from miscellaneous locations (fold change: 2.35 and 3.9, respectively; Table 7). PDGF-A and PDGF-C gene expression levels were upregulated in the FSCC from the oral region (fold change: 1.58 and 1.82, respectively; Table 7). However, PDGF-A gene expression levels were downregulated (fold change: 0.72; Table 7) in the FSCC originating from the ear, eyelid and nose with no statistically significant difference. Similarly, PDGF-C gene expression level was also downregulated (fold change: 0.53 ) in the FSCC from the ear, eyelid and nose with statistically significant difference $(P=0.028$; Table 7$)$. On the other hand, VEGF gene expression, compared to other genes, was significantly upregulated in both the FSCC from the oral region and in those from the ear, eyelid and nose (fold change: 64.4 and 60.02, respectively; Table 7).When we considered only tumour grades without tumour location, there was a tendency of decrease for the bFGF, TGF- $\beta$, PDGF-A, and PDGFR- $\alpha$ gene expression levels parallel to the increase in tumour grades, but the difference was not statistically significant with the exception of PDGFR- $\alpha$ in which the difference was statistically significant for grade 3 FSCC $(P=0.0078$; Table 8$)$. However, a different tendency was noted for the PDGF-C gene expression level. PDGF-C gene expression was the lowest in grade 1 FSCC $(P=0.0128)$. PDGF-C gene expression was elevated in grade 2 and grade 3 FSCC without a statistically

Table 7. RT-PCR scores for the gene expression levels with respect to GAPDH in the FSCC cases considering only tumour location

\begin{tabular}{lrcccccc}
\hline SCC location & $n$ & bFGF & VEGF-C & TGF- $\beta$ & PDGF-A & PDGF-C & PDGFR- $\alpha$ \\
\hline Oral region & 7 & $0.20 \pm 0.12$ & $64.40 \pm 50.45$ & $0.98 \pm 0.35$ & $1.58 \pm 1.26$ & $1.82 \pm 1.01$ & $0.23 \pm 0.09$ \\
Ear, eyelid, nose & 18 & $0.85 \pm 0.58$ & $60.02 \pm 34.69^{\mathrm{a}}$ & $0.99 \pm 0.23$ & $0.72 \pm 0.30$ & $0.53 \pm 0.26^{\mathrm{a}}$ & $0.68 \pm 0.22$ \\
Other & 1 & $2.35 \pm 0.00$ & $0.21 \pm 0.00$ & ND & $3.90 \pm 0.00$ & $1.05 \pm 0.00$ & ND \\
Control & 5 & $1.00 \pm 0.00$ & $1.00 \pm 0.00^{\mathrm{b}}$ & $1.00 \pm 0.00$ & $1.00 \pm 0.00$ & $1.00 \pm 0.00^{\mathrm{b}}$ & $1.00 \pm 0.00$ \\
\hline
\end{tabular}

Values are presented as mean \pm SE; ND: not done; $a$, b, column groups denoted with different letters indicate statistically significant difference $(P<0.05)$.

Table 8. RT-PCR scores for the gene expression levels with respect to GAPDH in the FSCC cases considering only tumour grade

\begin{tabular}{|c|c|c|c|c|c|c|c|}
\hline Grade & $n$ & bFGF & VEGF-C & TGF- $\beta$ & PDGF-A & PDGF-C & PDGFR- $\alpha$ \\
\hline 1 & 10 & $0.96 \pm 0.90$ & $30.70 \pm 24.46$ & $1.01 \pm 0.33$ & $1.10 \pm 0.48^{\mathrm{a}}$ & $0.25 \pm 0.13$ & $0.83 \pm 0.33$ \\
\hline 2 & 5 & $1.23 \pm 1.12$ & $85.37 \pm 76.76$ & $1.49 \pm 0.44$ & $1.03 \pm 0.77$ & $1.53 \pm 0.99$ & $0.23 \pm 0.02$ \\
\hline 3 & 12 & $0.42 \pm 0.26$ & $80.87 \pm 59.51^{\mathrm{a}}$ & $0.76 \pm 0.17$ & $0.94 \pm 0.71$ & $1.39 \pm 0.71$ & $0.33 \pm 0.09^{\mathrm{a}}$ \\
\hline Control & 5 & $1.00 \pm 0.00$ & $1.00 \pm 0.00^{\mathrm{b}}$ & $1.00 \pm 0.00$ & $1.00 \pm 0.00^{\mathrm{b}}$ & $1.00 \pm 0.00$ & $1.00 \pm 0.00^{b}$ \\
\hline
\end{tabular}

Values are presented as mean $\pm \mathrm{SE}$; $\mathrm{a}, \mathrm{b}$, column groups denoted with different letters indicate statistically significant difference $(P<0.05)$. 
significant difference (Table 8). The most striking difference was observed in the VEGF-C gene expression levels. VEGF$\mathrm{C}$ gene expression level was upregulated in grade 1, 2, and 3 FSCC cases and the fold change was $30.69,85.37$ and 80.87 , respectively (Table 8 ).

\section{DISCUSSION}

In the present study we evaluated the expression level of angiogenic growth factors in FSCCs. The results revealed altered expressions of bFGF, VEGF-C, TGF- $\beta$, PDGF-A, PDGF-C, and PDGFR $\alpha$ in these tumours. These findings indicate that growth factors may contribute to the development of FSCC in a similar way as in the case of human SCC (Ninck et al., 2003) and feline mammary tumours (Sarli et al., 2007).

The PDGF family consists of five dimeric isoforms (PDGF-AA, PDGFA-B, PDGF-BB, PDGF-CC and PDGF$\mathrm{DD})$, which exert their cellular effects via activation of structurally similar $\alpha$ and $\beta$ receptors. PDGF overexpression has been correlated with tumour growth and angiogenesis (Heldin and Westermark, 1999). PDGFs are important both in the autocrine stimulation of tumour cells and in paracrine signalling between them. Overexpression of PDGFs and their receptors was reported in human carcinomas (Lasota et al., 2006; Gockel et al., 2008). In the present study, the highest PDGFR- $\alpha$ protein signals were recorded from FSCC originating from the oral mucosa. Furthermore, FSCC immunoreactivity scores for PDGFR- $\alpha$ from the oral mucosa were elevated in the poorly differentiated (Grade 3) FSCC cases. However, the immunoreactivity scores did not differ significantly in relation to the grades of tumours from the ear, eyelids and nose and FSCC from other areas. Comparable results have been published for other tumour entities: it was reported that PDGFR- $\alpha$ was overexpressed in canine anaplastic oligodendrogliomas (Higgins et al., 2010). PDGFR- $\alpha$ expression has also been reported in human gastrointestinal stromal tumours (Lasota et al., 2006) as well as in human oesophageal SCC (Gockel et al., 2008). The high expression rate of PDGFR- $\alpha$ in FSCC occurring in the oral region implies a similar relevant role of PDGFR $-\alpha$ in FSCC.

Anti-PDGF-A antibody recognises PDGF-A chain-containing molecules, PDGF-AA and PDGF-AB. PDGF-A released by tumour cells induces proliferation and migration of endothelial cells and vascular smooth muscle cells, suggesting a direct role for PDGF-A in angiogenesis (Cao et al., 2004). In human gastric cancers, high levels of PDGF-A correlate with high-grade carcinomas and reduced patient survival time (Katano et al., 1998). Furthermore, PDGF-AB was detectable in two-thirds of human head and neck SCC, exerting growth-promoting properties (Montag et al., 2009). In a recent study, PDGF-A upregulation was responsible for re-initiated interferon alpha treatment in human hepatocellular carcinomas (Zhang et al., 2012). The present study indicates that PDGF-A protein secretion was significantly elevated in FSCC compared to normal control tissues.
Therefore, upregulated PDGF-A expression during carcinogenesis may contribute to the proliferation and survival of cancer cells via paracrine and autocrine stimulation. PDGF-A and PDGFR- $\alpha$ were simultaneously upregulated during the progression of FSCC. This corresponding expression of the PDGF-A and PDGFR- $\alpha$ signal suggests that the ligand of PDGF-A and its receptor may play a role in the carcinogenesis of FSCC, through the activation of the downstream signalling pathways. The PDGF-A autocrine loop is attributed to the co-expression of PDGF-A and PDGF-B together with their receptors (Nister et al., 1991). PDGF-A derived from tumour cells promoted the recruitment of PDGFR- $\alpha$ and induced tumour angiogenesis (Dong et al., 2004). Furthermore, we confirmed the upregulated expression of PDGF-A and PDGFR- $\alpha$ in FSCC. The present results are in agreement with those on human carcinomas (Ito et al., 1990). They suggest that PDGF ligands and receptors may be regarded as major players in the development of SCC, potentially playing a complex role in the regulation of the PDGF-A signalling pathway between endothelial, stromal and tumour cells in both an autocrine and a paracrine fashion.

In the present study, the highest IRS score for the PDGF-C antibody (IRS: $65 \pm 25$ ) was recorded in FSCC from the perineal region and the mandibular joint, as compared to the oral area and the ear, eyelids and nasal planum. However, the limited number of cases analysed for these areas limits the significance of this finding. There was no significant relation between tumour grade and PDGF-C staining intensity, regardless tumour location. The PDGF-C expression levels were upregulated in human lung cancers, indicating the tumour-promoting role of PDGF-C (Donnem et al., 2007). PDGF-C autocrine signalling has also been suggested to play a role in the initiation and progression of human cancers (Hurst et al., 2012). In the present study the finding of PDGF-C produced by tumour cells in FSCC indicates that PDGF-C is a mediator of SCC progression in cats.

VEGF is one of the most commonly studied lymphangiogenic growth factors, and various studies have suggested that VEGF secretion by tumour cells is a prerequisite for the development of human head and neck SCCs and human oral SCCs (Ali, 2008; Bran et al., 2009). VEGF expression and the correlation between VEGF and tumour lymphangiogenesis in canine cutaneous SCCs (AlDissi et al., 2007) and feline and canine mammary tumours (Millanta et al., 2002; Sarli et al., 2007) have been well established. In the present study, VEGF-C was found to be expressed in healthy feline skin tissues. Similarly, VEGF was shown to be expressed and secreted by epidermal keratinocytes for increasing cellular proliferation in humans (Man et al., 2006). In the present study, we found limited VEGF-C protein staining in FSCC originating from the oral region, ear, eyelid and nose compared to healthy control tissues. However, VEGF mRNA level was significantly elevated in the FSCC cases. This discordant protein and mRNA expression level for VEGF in FSCC cases was possibly due to translational and post-translational modifications or decreased protein levels causing a positive 
feedback on the mRNA level (Chen et al., 2002). It was reported that there is a close correlation between the level of VEGF-C and lymph node metastasis, early relapse and reduced survival in human oral SCC (Seki et al., 2011). Moussai et al. (2011) suggested that elevated VEGF expression indicates aggressive biological behaviour in human cutaneous SCCs. Similarly, VEGF-C expression was correlated with the depth of tumour invasion, tumour stage and lymph node metastasis in human oesophageal cancers (Kitadai et al., 2001), indicating a high relevance of VEGF-C for tumour progression.

It is well established that bFGF overexpression is critical for angiogenesis, tumour invasion and metastasis (Nakashio et al., 2002). Early studies demonstrated the presence of bFGF in human oral (Myoken et al., 1994; Janot et al., 1995) as well as head and neck SCC (Ninck et al., 2003). In the present study, increasing malignancy was reflected in decreased bFGF protein labelling scores, but with no statistically significant difference. In agreement with to our findings, Janot et al. (1995) recorded an inverse correlation between tumour malignancy and bFGF expression levels in human oral SCC. However, another study revealed an equal level of positivity for both well-differentiated and poorly differentiated human SCC cell lines (Myoken et al., 1994). On the other hand, another study showed a strict association between elevated bFGF synthesis and invasive growth, vessel invasion, angiogenesis, and regional and distant metastases in human gastric cancers (Zhang et al., 2009) and human head and neck SCCs (Montag et al., 2009). These findings contradict the results of Nakamura et al. (2005) according to which bFGF was associated with a good prognosis in human SCCs of the oesophagus. These reports indicate that bFGF contributes to angiogenesis and consequently to tumour invasion and metastasis in a complex manner depending on the location of the tumour, and that it might also reflect species-specific differences.

In the present study we also investigated TGF- $\beta$ protein expression in FSCC. The role of TGF- $\beta$ in carcinogenesis is not clearly understood as TGF- $\beta$ may play a dual role as a tumour suppressor or inducer during carcinogenesis. The tumour suppressor effects of TGF- $\beta$ in normal cells include apoptosis induction, maintaining genomic stability and tissue architecture, inducing senescence, and preventing immortalisation. Recent reports have suggested that TGF- $\beta$ could function as a tumour promoter in early human SCC (Davies et al., 2012). In fact, increased TGF- $\beta$ levels are associated with poor prognosis in many types of cancer, enhancing tumour invasion via the paracrine effects of TGF- $\beta$ on tumour stroma, maintaining cancer stem cell phenotype, controlling cellular differentiation of cancer cells, modulating angiogenesis, and immunosuppression (Ulloa et al., 1999; Bitzer et al., 2000). In our study, in line with the results of Logullo et al. (2003), TGF- $\beta$ scores were negatively correlated with tumour grade in FSCC originating from the cheek and retromandibular area (other regions; Table 6). However, the limited number of cases available from these areas limits the significance of this finding. On the other hand, in conformity with the literature regarding FSCC originating from the oral region, TGF$\beta$ scores were found to be positively correlated with tumour grade (Davies et al., 2012). Nevertheless, no such relationships were demonstrated between tumour grade and the TGF- $\beta$ scores of FSCC from the ear, eyelids and nose. However, the levels of expression of TGF- $\beta$ in human cutaneous SCC have been studied previously, and it has been demonstrated that expression of the ligand increases progressively during carcinogenesis from normal skin to SCC (Han et al., 2005). It is interesting to note that in the present study the immunohistochemical expression of TGF- $\beta$ either showed an extremely low level of staining or was negative in FSCC from the ear, eyelids and nose, as was seen in the control skin samples. In fact, the low levels of TGF- $\beta$ in tumour cells can account for the relative resistance to the growth inhibitory activity of TGF- $\beta$. Similarly, the reduced TGF- $\beta$ expression in human high-grade oral SCCs indicated the progressive reduction of the growthcontrolling role of the TGF- $\beta$ system (Mincione et al., 2008). These observations suggest the possibility that downregulation and upregulation of the TGF- $\beta$ system play a key role in the progression of FSCC depending on its origin and location.

In the present study we examined if there were localisation-dependent differences in growth factor expression levels and tumour grades by analysing FSCC mainly derived from three different locations, namely the oral region, areas exposed to solar UV radiation including the ear, eyelids, and nasal planum, and other miscellaneous locations. We found that FSCC arising from different anatomical sites of the body showing differences in aggressiveness, metastasis, and prognosis are angiogenesis dependent, and that key angiogenic regulators play a certain role in the development of FSCC. In the present study, the significant elevation of VEGF-C mRNA levels, but not protein staining, supports the notion that FSCC are angiogenesis dependent and reveals that their behavioural characteristics are similar to those of human SCCs. The growth factors analysed in this study should be further evaluated for their prognostic significance in FSCC. Furthermore, the significant interactions of certain growth factors in common regulatory pathways indicate that they are good candidates for targeted therapies. However, it is essential to develop multidirectional therapy strategies covering all possible aspects of growth factors involved in angiogenesis. Large-scale studies should be conducted to reveal the distinct roles of these signalling pathways in the progression of naturally occurring FSCC.

\section{ACKNOWLEDGEMENT}

This study was financially supported by Ondokuz Mayis University Scientific Research and Development Support Program (Project No.: PYO.VET.1901.13.001), Samsun, Turkey. 


\section{REFERENCES}

Akhurst, R. J. and Derynck, R. (2001): TGF- $\beta$ signalling in cancer a double-edged sword. Trends Cell. Biol. 11, S44-S51.

Al-Dissi, A. N., Haines, D. M., Singh, B. and Kidney, B. A. (2007): Immunohistochemical expression of vascular endothelial growth factor and vascular endothelial growth factor receptor associated with tumor cell proliferation in canine cutaneous squamous cell carcinomas and trichoepitheliomas. Vet. Pathol. 44, 823-830.

Ali, M. A. (2008): Lymphatic microvessel density and the expression of lymphoangiogenic factors in oral squamous cell carcinoma. Med. Princ. Pract. 17, 486-492.

Alvarez, R. H., Kantarjian, H. M. and Cortes J. E. (2006): Biology of platelet-derived growth factor and its involvement in disease. Mayo Clin. Proc. 81, 1241-1257.

Andrae, J., Gallini, R. and Betsholtz, C. (2008): Role of plateletderived growth factors in physiology and medicine. Genes Dev. 22, 1276-1312.

Asahara, T., Bauters, C., Zheng, L. P., Takeshita, S., Bunting, S., Ferrara, N., Symes, J. F. and Isner, J. M. (1995): Synergistic effect of vascular endothelial growth factor and basic fibroblast growth factor on angiogenesis in vivo. Circulation. 92, 365-371.

Bitzer, M., von Gersdorff, G., Liang, D., Dominguez-Rosales, A., Beg. A. A., Rojkind, M. and Bottinger, E. P. (2000): A mechanism of suppression of TGF-s/SMAD signalling by NF-kappa B/RelA. Gene Dev. 14, 187-197.

Bran, B., Bran, G., Hörmann, K. and Riedel, F. (2009): The plateletderived growth factor receptor as a target for vascular endothelial growth factor-mediated anti-angiogenetic therapy in head and neck cancer. Int. J. Oncol. 34, 255-261.

Breslin, J. W., Pappas, P. J., Cerveira, J. J., Hobson, R. W. and Durán, W. N. (2003): VEGF increases endothelial permeability by separate signaling pathways involving ERK-1/2 and nitric oxide. Am. J. Physiol. Heart Circ. Physiol. 284, 92100.

Cao, R., Bjorndahl, M. A., Religa, P., Clasper, S., Garvin, S., Galter, D., Meister, B., Ikomi, F., Tritsaris, K., Dissing, S., Ohhashi, T., Jackson, D. G. and Cao, Y. (2004): PDGF-BB induces intratumoral lymphangiogenesis and promotes lymphatic metastasis. Cancer Cell. 6, 333-345.

Chen, G., Gharib, T. G., Huang, C. C., Taylor, J. M., Misek, D. E., Kardia, S. L., Giordano, T. J., Iannettoni, M. D., Orringer, M. B., Hanash, S. M. and Beer, D. G. (2002): Discordant protein and mRNA expression in lung adenocarcinomas. Mol. Cell. Proteomics 1, 304-313.

Cheung, C. Y. and Brace, R. A. (1998): Ovine vascular endothelial growth factor: nucleotide sequence and expression in fetal tissues. Growth Factors 16, 11-22.

Davies, M., Prime, S. S., Eveson, J. W., Price, N., Ganapathy, A., D’Mello, A. and Paterson, I. C. (2012): Transforming growth factor- $\beta$ enhances invasion and metastasis in Ras-transfected human malignant epidermal keratinocytes. Int. J. Exp. Pathol. 93, 148-156.

Dong, J., Grunstein, J., Tejada, M., Peale, F., Frantz, G., Liang, W. C., Bai, W., Yu, L., Kowalski, J., Liang, X., Fuh, G., Gerber, H. P. and Ferrara, N. (2004): VEGF-null cells require PDGFR $\alpha$ signaling-mediated stromal fibroblast recruitment for tumorigenesis. EMBO J. 23, 2800-2810.

Donnem, T., Al-Saad, S., Al-Shibli, K. Delghandi, M. P., Persson, M., Nilsen, M. N., Busund, L. T. and Bremnes, R. M. (2007): Inverse prognostic impact of angiogenic marker expression in tumor cells versus stromal cells in non-small cell lung cancer. Clin. Cancer Res. 13, 6649-6657.

Feng, X. H. and Derynck, R. (2005): Specificity and versatility in TGF-beta signaling through SMADS. Annu. Rev. Cell Dev. Biol. 21, 659-693.

Ferrara, N. and Davis-Smith, T. (1997): The biology of vascular endothelial growth factor. Endocr. Rev. 18, 4-25.

Galzie, Z., Kinsella, A. R. and Smith, J. A. (1997): Fibroblast growth factors and their receptors. Biochem. Cell Biol. 75, 669-685.

Gazit, A., Igarashi, H., Chiu, I. M., Srinivasan, A., Yaniv, A., Tronick, S. R., Robbins, K. C. and Aaronson, S. A. (1984): Expression of the normal human sis/PDGF-2 coding sequence induces cellular transformation. Cell 39, 89-97.

Gockel, I., Moehler, M., Frerichs, K., Drescher, D., Trinh, T. T., Duenschede, F., Borschitz, T., Schimanski, K., Biesterfeld, S., Herzer, K., Galle, P. R., Lang, H., Junginger, T. and Schimanski, C. C. (2008): Co-expression of receptor tyrosine kinases in esophageal adenocarcinoma and squamous cell cancer. Oncol. Rep. 20, 845-850.

Goldschmidt, M. H., Dunstan, R. W., Stannard, A. A. von Tscharner, C., Walder, E. J. and Yager, J. A. (1998): Histological Classification of Epithelial and Melanocytic Tumors of the Skin of Domestic Animals, 2nd edition. Armed Forces Institute of Pathology, Washington. pp. 18-21.

Gross, T. L., Ihrke, P. J., Walder, E.J. and Affolter, W. K. (2005): Squamous cell carcinoma. In: Skin Diseases of the Dog and Cat. Clinical and Histopathological Diagnosis. Second edn. WileyBlackwell, Iowa. pp. 581-589.

Han, G., Lu, S. L., Li, A. G., He, W., Corless, C. L., Kulesz-Martin, M. and Wang, X. J. (2005): Distinct mechanisms of TGF-beta1mediated epithelial-to-mesenchymal transition and metastasis during skin carcinogenesis. J. Clin. Invest. 115, 1714-1723.

Hasina, R., Whipple, M., Martin, L., Kuo, W. P., Ohno-Machado, L. and Lingen, M. W. (2008): Angiogenic heterogeneity in head and neck squamous cell carcinoma: biological and therapeutic implications. Lab. Invest. 88, 342-353.

Heldin, C. H. and Westermark, B. (1999): Mechanism of action and in vivo role of platelet-derived growth factor. Physiol. Rev. 79, 1283-1316.

Higgins, R. J., Dickinson, P. J., LeCouteur, R. A., Bollen, A. W., Wang, H., Wang, H., Corely, L. J., Moore, L. M., Zang, W. and Fuller, G. N. (2010): Spontaneous canine gliomas: overexpression of EGFR, PDGFRalpha and IGFBP2 demonstrated by tissue microarray immunophenotyping. J. Neuro Oncol. 98, 49-55.

Hurst, N. J., Jr., Najy, A. J., Ustach, C. V., Movilla, L. and Kim, H. R. (2012): Platelet-derived growth factor-C (PDGF-C) activation by serine proteases; implications for breast cancer progression. Biochem. J. 441, 909-918.

Ito, M., Yoshida, K., Kyo, E., Ayhan, A., Nakayama, H., Yasui, W., Ito, H. and Tahara, E. (1990): Expression of several growth factors and their receptor genes in human colon carcinomas. Virchows Arch. B Cell Pathol. Incl. Mol. Pathol. 59, 173-178. 
Janot, F., el-Naggar, A. K., Morrison, R. S, Liu, T. J., Taylor, D. L. and Clayman, G. L. (1995): Expression of basic fibroblast growth factor in squamous cell carcinoma of the head and neck is associated with degree of histologic differentiation. Int. J. Cancer. 64, 117-123.

Katano, M., Nakamura, M., Fujimoto, K., Miyazaki, K. and Morisaki, T. (1998): Prognostic value of platelet derived growth factor-A (PDGF-A) in gastric carcinoma. Ann. Surg. 227, 365-371.

Katayama, R., Huelsmeyer, M. K., Marr, A. K., Kurzman, I. D., Thamm, D. H. and Vail, D. M. (2004): Imatinib mesylate inhibits platelet-derived growth factor activity and increases chemosensitivity in feline vaccine-associated sarcoma. Cancer Chemother. Pharmacol. 54, 25-33.

Kitadai, Y., Amioka, T., Haruma, K., Tanaka, S., Yoshihara, M., Sumii, K., Matsutani, N., Yasui, W. and Chayama, K. (2001): Clinicopathological significance of vascular endothelial growth factor (VEGF)-C in human esophageal squamous cell carcinomas. Int. J. Cancer 93, 662-666.

Kowanetz, M. and Ferrara, N. (2006): Vascular endothelial growth factor signaling pathways: therapeutic perspective. Clin. Cancer Res. 12, 5018-5022.

Lasota, J., Stachura, J. and Miettinen, M. (2006): GISTs with PDGFRA exon 14 mutations represent subset of clinically favourable gastric tumors with epitheloid morphology. Lab. Invest. 86, 94-100.

Logullo, A. F., Nonogaki, S., Miguel, R. E., Kowalski, L. P., Nishimoto, I. N., Pasini, F. S., Federico, M. H. H., Brentani, R. R. and Brentani, M. M. (2003): Transforming growth factor betal (TGFbeta1) expression in head and neck squamous cell carcinoma patients as related to prognosis. J. Oral Pathol. Med. 32, 139-145.

Man, X. Y., Yang, X. H., Cai, S. Q., Yao, Y. G. and Zheng, M. (2006): Immunolocalization and expression of vascular endothelial growth factor receptors (VEGFRs) and neuropilins (NRPs) on keratinocytes in human epidermis. Mol. Med. 12, 127-136.

Millanta, F., Lazzeri, G., Vannozzi, I., Viacava, P. and Poli, A. (2002): Correlation of vascular endothelial growth factor expression to overall survival in feline invasive mammary carcinomas. Vet. Pathol. 39, 690-696.

Miller, M. A., Nelson, S. L., Turk, J. R., Pace, L.W., Brown, T. P., Shaw D. P., Fischer J. R. and Gosser, H. S. (1991): Cutaneous neoplasia in 340 cats. Vet. Pathol. 28, 389-395.

Mincione, G., Di Marcantonio, M. C., Artese, L., Vianale, G., Piccirelli, A., Piccirilli, M., Perrotti, V., Rubini, C., Piattelli, A. and Muraro, R. (2008): Loss of expression of TGF-B1, TßRI, and TBRII correlates with differentiation in human oral squamous cell carcinomas. Int. J. Oncol. 32, 323-331.

Montag, M., Dyckhoff, G., Lohr, J., Helmke, B. M., Herrmann, E., Plinkert, P. K. and Herold-Mende, C. (2009): Angiogenic growth factors in tissue homogenates of HNSCC: expression pattern, prognostic relevance and interrelationships. Cancer Sci. 100, 1210-1218.

Moussai, D., Mitsui, H., Pettersen, J. S., Pierson, K. C., Shah, K. R., Suárez-Fariñas, M., Cardinale, I. R., Bluth, M. J., Krueger, J. G. and Carucci, J. A. (2011): The human cutaneous squamous cell carcinoma microenvironment is characterized by increased lymphatic density and enhanced expression of macrophagederived VEGF-C. J. Invest. Dermatol. 131, 229-236.

Myoken, Y., Myoken, Y., Okamoto, T., Sato, J. D. and Takada, K. (1994): Immunocytochemical localization of fibroblast growth factor-1 (FGF-1) and FGF-2 in oral squamous cell carcinoma (SCC). J. Oral Pathol. Med. 23, 451-456.

Nakamura, T., Ozawa, S., Kitagawa, Y., Shih, C. H., Ueda, M. and Kitajima, M. (2005): Expression of basic fibroblast growth factor is associated with a good outcome in patients with squamous cell carcinoma of the esophagus. Oncol. Rep. 14, 617-623.

Nakashio, A., Fujita, N. and Tsuruo, T. (2002): Topotecan inhibits VEGF- and bFGF-induced vascular endothelial cell migration via downregulation of the PI3K-Akt signaling pathway. Int. J. Cancer. 98, 36-41.

Ninck, S., Reisser, C., Dyckhoff, G., Helmke, B., Bauer, H. and Herold-Mende, C. (2003): Expression profiles of angiogenic growth factors in squamous cell carcinomas of the head and neck. Int. J. Cancer. 106, 34-44.

Nister, M., Claesson-Welsh, L., Eriksson, A., Heldin, C. H. and Westermark, B. (1991): Differential expression of plateletderived growth factor receptors in human malignant glioma cell lines. J. Biol. Chem. 266, 16755-16763.

Ostman, A. and Heldin, C. H. (2007): PDGF receptors as targets in tumor treatment. Adv. Cancer Res. 97, 247-274.

Pierce, D. F., Jr., Gorska, A. E., Chytil, A., Meise, K. S., Page, D.L., Coffey, R. J., Jr. and Moses, H. L (1995): Mammary tumor suppression by transforming growth factor- $\beta 1$ transgene expression. Proc. Natl. Acad. Sci. USA. 92, 42544258.

Ross, R., Raines, E. W. and Bowen-Pope, D. F. (1986): The biology of platelet-derived growth factor. Cell. 46, 155-169.

Sarli, G., Sassi, F., Brunetti, B. Rizzo, A., Diracca, L. and Benazzi, C. (2007): Lymphatic vessels assessment in feline mammary tumors. BMC Cancer. 7, 7.

Seki, S., Fujiwara, M., Matsuura, M., Fujita, S., Ikeda, H., Asahina, I. and Ikeda, T. (2011): Prediction of outcome of patients with oral squamous cell carcinoma using vascular invasion and the strongly positive expression of vascular endothelial growth factors. Oral. Oncol. 47, 588-593.

Ulloa, L., Doody, J. and Massague, J. (1999): Inhibition of transforming growth factor-s/SMAD signalling by the interferon- $\gamma /$ STAT pathway. Nature. 397, 710-713.

Veikkola, T. and Alitalo, K. (1999): VEGFs, receptors and angiogenesis. Semin. Cancer Biol. 9, 211-220.

Wang, X. J. (2001): Role of TGFbeta signaling in skin carcinogenesis. Micros. Res. Tech. 52, 420-429.

Weinberg, A. S., Ogle, C. A. and Shim, E. K. (2007): Metastatic cutaneous cell carcinoma: an update. Dermatol. Surg. 33, 885899.

Wilcock, B. P. (2006): Eye and ear. In: Maxie, M. G. (ed) Jubb, Kennedy, and Palmer's Pathology of Domestic Animals. W. B. Saunders Co., Philadelphia. pp. 534-536.

Witte, D., Thomas, A., Ali, N., Carlson, N. and Younes, M. (2002): Expression of the vascular endothelial growth factor receptor-3 (VEGFR-3) and its ligand VEGF-C in human colorectal adenocarcinoma. Anticancer Res. 22, 1463-1466. 
Yoshiji, H., Gomez, D. E., Shibuya, M. and Thorgeirsson, U. P. (1996): Expression of vascular endothelial growth factor, its receptor, and other angiogenic factors in human breast cancer. Cancer Res. 56, 2013-2016.

Zhang, J. B., Sun, H. C., Jia, W. D., Zhuang, P. Y., Qian, Y.B., Zhu, X. D., Kong, L. Q., Wang, L., Wu, W. Z. and Tang, Z. Y. (2012): Up-regulation of platelet-derived growth factor-A is responsible for the failure of re-initiated interferon alpha treatment in hepatocellular carcinoma. BMC Cancer. 12, 439.

Zhang, W., Chu, Y. Q., Ye, Z. Y., Zhao, Z. S. and Tao, H. Q. (2009): Expression of hepatocyte growth factor and basic fibroblast growth factor as prognostic indicators in gastric cancer. Anat. Rec. (Hoboken) 292, 1114-1121. 